\title{
Facilitating knowledge management through filtered big data: SME competitiveness in an agri-food sector
}

\author{
Christina O'Connor and Stephen Kelly
}

\author{
Christina O'Connor is \\ based at Maynooth \\ University, Maynooth, \\ Ireland. Stephen Kelly is \\ based at Massey \\ University, Palmerston \\ North, New Zealand.
}

Received 30 August 2016 Revised 4 October 2016 14 October 2016 Accepted 14 October 2016

\begin{abstract}
Purpose - This paper aims to critique a facilitated knowledge management $(K M)$ process that utilises filtered big data and, specifically, the process effectiveness in overcoming barriers to small and medium-sized enterprises' (SMEs') use of big data, the processes enablement of SME engagement with and use of big data and the process effect on SME competitiveness within an agri-food sector.

Design/methodology/approach - From 300 participant firms, SME owner-managers representing seven longitudinal case studies were contacted by the facilitator at least once-monthly over six months. Findings - Results indicate that explicit and tacit knowledge can be enhanced when SMEs have access to a facilitated programme that analyses, packages and explains big data consumer analytics captured by a large pillar firm in a food network. Additionally, big data and knowledge are mutually exclusive unless effective KM processes are implemented. Several barriers to knowledge acquisition and application stem from SME resource limitations, strategic orientation and asymmetrical power relationships within a network.

Research limitations/implications - By using Dunnhumby data, this study captured the impact of only one form of big data, consumer analytics. However, this is a significant data set for SME agri-food businesses. Additionally, although the SMEs were based in only one UK region, Northern Ireland, there is wide scope for future research across multiple UK regions with the same Dunnhumby data set.

Originality/value - The study demonstrates the potential relevance of big data to SMEs' activities and developments, explicitly identifying that realising this potential requires the data to be filtered and presented as market-relevant information that engages SMEs, recognises relationship dynamics and supports learning through feedback and two-way dialogue. This is the first study that empirically analyses filtered big data and SME competitiveness. The examination of relationship dynamics also overcomes existing literature limitations where SMEs' constraints are seen as the prime factor restricting knowledge transfer.
\end{abstract}

Keywords Case studies, Knowledge management, SMEs, Big data, Agri-food

Paper type Research paper

\section{Introduction}

The context for this paper is a facilitated knowledge management (KM) process that utilises filtered big data within an agri-food supply chain. It specifically examines the ability of small- and medium-sized businesses (SMEs) to overcome barriers to big data use, to enable SMEs to engage with big data and to impact positively on small business competitiveness. The big data of interest is that of big data consumer analytics, defined as the "extraction of hidden insights about consumer behaviour from big data and the exploitation of that insight through advantageous interpretation" (Erevelles et al., 2015, p. 897). The specific big data consumer analytics examined is those of the "Tesco Clubcard data", otherwise known as "Dunnhumby data"[1]. This data comprise of 40 per cent of all UK households (approximately 17 million customers), with 10 per cent of this customer data being processed every two weeks using a rolling ball algorithm (Donnelly et 
al., 2015). The co-founder of Dunnhumby has argued that "You need to look at real (consumer) behaviour, real motivation, and you need to link all that knowledge" (Dunn, 2006, p. 47) to make informed business decisions.

The research was embedded within a novel and experimental three-year project launched in Northern Ireland through the Department of Agriculture and Rural Development (DARD) in association with the Ulster University. The project's focus on SMEs was in part prompted by an agri-food report titled "Fit for Market" (2004) led by the Food Strategy Group, which highlighted the lack of information flow within businesses and how that was impacting on SME competitiveness at local, regional and national levels. This pivotal report paved the way for further strategic action plans by the Agri-food Strategy Board AFSB(2013) in "Going for Growth" in planning for a 2020 Vision for Northern Ireland's agri-food sector.

Literature examining SMEs, big data and KM was integrated and two research questions were formulated. These research questions were addressed through undertaking seven longitudinal case studies selected from a larger cohort of 300 firms that engaged with the Dunnhumby project[2]. The two research questions specifically addressed are:

$R Q 1$. What are the barriers to and enablers of SME engagement with big data, and how might these be overcome and/or aided through engagement with a facilitated big data process?

$R Q 2$. Does engagement with big data made available through a facilitated knowledge management process affect SME understanding of big data, SME market knowledge, and SME competitiveness?

\section{Literature review}

The literature characterises SMEs as unique, informal, reactive, resource tight and possessing flexible structures (Wincent, 2005; Donnelly et al., 2015). Ultimately, it is recognised that "a small business is not a little big business" (Welsh and White, 1981), with firm size and strategic orientation being significant factors influencing the firm's behaviour, performance (Coviello et al., 2000, p. 526) and response to highly formalised market intelligence data (Donnelly et al., 2015).

However, while SMEs operate under diverse frames of reference, display varied patterns of behaviour and are driven by a myriad of motivations, it is reasonable to state that SME competiveness is generally derived from their agility, responsiveness and/or focus, rather than the accumulation and deployment of substantial proprietary resources. It is also evident that the influence of the owner-manager in an SME is amplified given the diversification and sharing of roles and close organisational proximity (Jennings and Beaver, 1997; Blackburn et al., 2013).

In the SME context, it can also be challenging to accumulate, analyse and accurately interpret data and transform that into codified and usable knowledge that is communicated effectively. The SME will often not possess the skills, time and resources they need to do this well, with the result being that the principal will make decisions based on intuitive rather than discursive reasoning. Potentially, this is a substantial limiting factor given that accurate, timely and contextual knowledge facilitates SME agility, responsiveness and focus.

In the following review of extant literature, big data, knowledge and KM within the SME context is examined, with an underlying presumption being that knowledge can be an asset underpinning SME competitiveness. This examination of knowledge and KM in an SME context is further focused through consideration of SME engagement with big data, and barriers and enablers to this engagement. We define KM in this paper as "the processes and structures provided in SMEs to support different knowledge processes, such as transfer, storage and creation" (Durst and Edvardsson, 2012, pp. 879-880). 


\section{Big data and knowledge management}

It is now trendy to be seen to be using big data, (Angiuli et al., 2015, p. 48), the so-called "next big thing in innovation" (Gobble, 2013, p. 34). There is also a growing prevalence of big data being used gathered across various industries from the government sector, internet businesses, to finance (Liu et al., 2014). It is a focus fuelled by academic and industry research which reports positive increases in companies' return on investment and deeper business insight as a result of analysing big data effectively (Perrey et al., 2013; Manyika et al., 2011).

At the "epicentre of the Big Data Revolution" is consumer analytics (Erevelles et al., 2015, p. 897). The idea that we are capturing all information, structured and unstructured, about the consumers in their daily life is now fully understood and expected by marketing practitioners in large multinationals. This information-gathering has the intent of "transforming marketing decision-making" (Erevelles et al., 2015, p. 898), with many firms exploring how to "professionally use the ever-increasing volume of data for better prediction of individual action, consumer choice, search behaviours and risk occurrences" (Zhao et al., 2015).

However, despite all this hype, there appears to be an element of uncertainty by adopters of big data as they seek to understand what it actually is and how to capture value from it (Wamba et al., 2015). Although technology and data have moved at great pace to advance businesses, arguably, this has not been accompanied by "increased information management capability" (Wamba et al., 2015). The challenge with this mass of consumer analytics is not so much how to access or store it but, more interestingly from a business perspective, "how to make sense of it?" A leading scholar in this area, Lycett (2013), defined this notion of making sense of big data as "Datafication" involving dematerialisation, liquification and density. Dematerialisation here refers to the ability to separate "the informational aspect and its use in context from the physical world"; liquification refers to the unbundling or rebundling of information; and density is the result of the value creation process with the best combination of resources and information.

\section{Small- and medium-sized enterprises, big data and knowledge management}

Literature examining big data and KM has primarily concentrated on larger businesses, a focus that could be linked to reports suggesting that "SMEs lack the financial strength to invest in technology" (Wee and Chua, 2013). However the critical role of SMEs in local and national economic development means that small businesses also need access to/understanding of big data (Donnelly and Simmons, 2013). If they do not have access, then there is an enhanced likelihood that a "deep divide between the have-datas and the have-no-datas" will be created (Donnelly and Simmons, 2013, p. 1), with data-dominated larger firms taking market share, customers and profits away from those which have no data (McAfee, 2013). It would be a competitive transition arguably driven by large companies which have access to, and analyse, big data, thus being able to make more data-driven decisions, which according to McAfee and Brynjolfsson (2012, p. 63) are "better decisions- it's as simple as that. Using big data enables managers to decide on the basis of evidence rather than intuition. For that reason it has the potential to revolutionize management".

However, to achieve a broad-based change in the culture of SME data use and decision-making would be revolutionary. As mentioned earlier, to date, SMEs have most often been successful by leveraging off their networks to extract important knowledge on and about the market (Wee and Chua, 2013), using decision-making that is more intuitive than discursive. SMEs are characterised by the personality of their owner-manager, and their generalist approach and commitment to running the business are instrumental in dictating the direction and success of their business performance and growth (Blackburn et al., 2013). The role of big data in decision-making almost appears to counteract the 
thinking and the "ways" of the owner-manager in their flexible, experience-driven and intuitive approach to decision-making.

The literature does provide a counterpoint to this apparent dichotomy between SME decision-making behaviour and big data use, suggesting that "big data's power does not erase the need for vision or human insight" (McAfee and Brynjolfsson, 2012, p. 65). Indeed, the argument has also been made that a complementary relationship can exist between the highly formalised nature of big data and the informal nature of the SME in its day-to-day marketing activities (Donnelly et al., 2015).

Recently, Massaro et al. (2016) undertook a comprehensive literature review of the KM literature within the SME context, noting that "knowledge management within SMEs is a research area of growing importance" (p. 1). However, they also noted that "only ten authors have published more than one paper in this area" (p. 18), suggesting this reflected a limitation in the literature. They also highlight Durst and Edvardsson's (2012) call for more research into what is given to SMEs rather than what should be given and conclude, in part, that scholars in KM need to develop research agendas that align to stakeholder needs, be focused on developing pragmatic research and involve policy makers in their research studies.

KM literature focused on SMEs has identified some recurring SME themes. These include the tendency for the SME owner, rather than employees, to act as the primary source and creator of knowledge internally (Wee and Chua, 2013), for resource limitations to restrict SME KM capabilities (Davenport et al., 1998), for SME principals to generally rely on tacit over explicit knowledge (Ghobadian and Gallear, 1996) and for SMEs to need to further develop their understanding of KM as a key business driver (McAdam and Reid, 2001). The literature also suggests that failure to benefit from big data often derives from big data's unique resource requirements (Erevelles et al., 2015, p. 897), with SMEs typically being at a "loss" when it comes to big data. Their capacity to purchase and use this data, create knowledge and enhance competitiveness is limited by their analytical skills, confidence and internal resource constraints.

\section{Small- and medium-sized enterprise competitiveness and strategy in terms of big data and knowledge management}

Within competitive advantage considerations, knowledge has emerged as one of the more strategic, although invisible, assets for organisations (Kakabadse et al., 2001, p. 137). Other sources of competitive advantage available to SMEs may include tangible assets such as land and equipment, industry training, efficient organisational processes (McDowell, Harris and Gehoa, 2015) or network effects (Kelly and Scott, 2012).

Knowledge generally, and in the SME context, can either be characterised as tacit or explicit ("codified") knowledge; it loosely underpins intuitive and discursive reasoning, respectively. Given the influence of the owner-manager within an SME, their tacit versus explicit knowledge preferences will likely be evident in the SME's strategic orientation. That is, SMEs presenting as prospectors and analysers would tend to seek information more aggressively and rely on knowledge that could be deemed explicit, while those presenting as defenders and reactors tend to be more conservative in their information search and rely on tacit knowledge. These strategic categorisations, developed by Miles and Snow (1978), designate a prospector as being a highly innovative firm that is constantly seeking out new markets and new opportunities and is oriented towards growth and risk taking; analysers as sharing many prospector traits while remaining more focused on the adoption of ideas generated by competitors, the maintenance of limited product lines and tight cost controls; defenders as concentrating on protecting their current markets, maintaining stable growth and serving their current customers; and reactors as perceiving significant risk in all things and generally being unwilling to change until they have to. 
This association between the strategic orientation of firms, as characterised by the Miles and Snow (1978) typology, and the information managers attend to, has been demonstrated in a large firm environment by Kabanoff and Brown (2008). In their study of knowledge structures used by top management teams, Kabanoff and Brown (2008) identified both a consistency over time and a distinct association with the strategic orientation used. Their findings also reinforced a trend in the literature identifying a performance gradient whereby prospectors and analysers generally outperform reactors and defenders.

Barney's (1991) resource-based view provides further support for our consideration of knowledge as a competitive asset. In his seminal article, Barney argued that competitive advantage derives from the resources and capabilities controlled by a firm that are valuable, rare, imperfectly imitable and not substitutable. As noted previously, knowledge is recognised as a strategic asset (Kakabadse et al., 2001), while the resource-based theory (RBT) has also been identified as a valuable theory for explaining big data's impact through knowledge generation on marketing (Erevelles et al., 2015).

For SMEs, the resource-based perspective represents a strategic conundrum as it is arguable that resource limitations directly impact upon SMEs' ability to engage with and understand big data, and that this limitation is amplified as it also restricts their ability to access, interpret and apply knowledge, an accepted strategic resource, to business opportunities and problems. Extending this logically, there is a likely connection between the strategic orientation of the SME, its willingness to apply scarce resources to accessing and interpreting data and the availability of explicit knowledge as a strategic resource.

As such, while the expertise available to an SME undoubtedly influences its ability to engage with and use big data effectively, the strategic orientation of the firm, which is invariably expressed as a function of the strategic orientation of the owner-manager, will likely influence the perceived value of explicit knowledge available in big data sets. That is, defenders and reactors would likely see less value in a big data analytics exercise, whereas prospectors and analysers would see an opportunity to discern information that would support discursive reasoning and add to the firm's strategic resource base.

\section{Small- and medium-sized enterprises, networks and knowledge management}

SMEs often reside within extended supply networks that offer knowledge that is potentially critical to the establishment of a sustainable competitive position within their respective markets. Similarly, the role of SMEs as active knowledge participants in networks can be critical, particularly "where the concentration of an SME's competitive advantage is through innovation" (Fletcher and Polychronakis, 2007, p. 194). However, the KM practices of many SMEs, which are frequently inextricably linked to the owner-manager, can undermine the SME's ability to establish effective KM practices that tap into data and knowledge held within these networks (Valkokari and Helander, 2007).

Knowledge acquisition barriers impacting on SMEs within networks are most often categorised in one of two ways. Firstly, there is the SME owner-manager's inclination to seek tacit knowledge that reinforces existing perspectives, and secondly, there are SME resource limitations that impact upon their ability to seek, analyse and interpret data that could support explicit knowledge acquisition.

In addition to these categories, for those who operate within distribution networks dominated by large, multi-national pillar firms, knowledge and power imbalances can also damage communication channels, with communication being undermined by perceptions that SMEs are beneficiaries who need assistance. The result of such a perception is that top-down rather than two-way communication ensues, and this is often reflexively rejected by SMEs that, almost by nature, are independent and seek equality. A more effective approach would be to incorporate appropriate systems enabling one-to-one engagement

PAGE 160 | JOURNAL OF KNOWLEDGE MANAGEMENT | VOL. 21 NO. 12017 
(Nolan, 2005), with the aim being to move SMEs away from intuitive and towards discursive reasoning. Fee et al., (2002) similarly highlight the unintentional barriers created by government agencies even when they are seeking to support SMEs within a government purchasing system. These unintentional barriers include an overabundance of paperwork, with bureaucratic language and lack of clarity on specifications, as well as a lack of staff professionalism.

Such network failures reflect in part an inability of inter-organisational interaction to support sense-making processes essential for creating mutual knowledge and expectations between network partners (Ring and van de Ven, 1994). By reference to Clegg's (1989) "Circuits of Power" model, it is arguable that a move by pillar firms in networks away from the provision of top-down information and towards the provision of symmetrical discourse that facilitates two-way learning and knowledge sharing would benefit all network members. It is an approach already evident in some networks, with Polychronakis et al. (2007) suggesting that some buyer-supplier relationships have evolved from passive relationships to partnerships for mutual benefit.

Literature pertaining to SMEs, big data, KM and competitiveness therefore provides insight into SME KM and preference limitations, the importance of knowledge as a competitive resource and barriers that exist within networks involving SMEs that restrict knowledge transfer, analysis and use. However, substantive research questions remain. The first of these to be addressed by this research is $R Q 1$ :

The literature provides preliminary insight by acknowledging SME resource limitations and SME principal knowledge preferences; extrapolation suggests that power imbalances within networks impact negatively upon relationship dynamics. However, this has not been empirically examined within the context of KM and specifically the availability and use of big data by SMEs.

$R Q 2$ examines the dynamics between big data use by SMEs and competitiveness.

The literature again provides insight, highlighting the role of knowledge as a strategic resource and suggesting that the strategic orientation of the firm as defined by Miles and Snow (1978) and the resource-based view introduced by Barney (1991) can be used as theoretical lenses to understand and explain SME behaviour as it pertains to big data KM. However, again, there has been limited empirical research focused on the subtleties that may exist between SMEs, big data and competitiveness.

\section{Methodology}

The choice of one type of big data consumer analytics in the form of Dunnhumby data can be justified by the immense data capture it provides of real-time consumer purchasing behaviour across all UK regions (Donnelly et al., 2015). This data set is typically purchased at a high cost by a larger firm for their own development. In this instance, the Department of Agriculture and Rural Development (DARD) in Northern Ireland paid for the cost of access and provision, at no charge to SMEs. This was the first initiative of its kind within the region of Northern Ireland to provide free access to such a costly data set for businesses. The marketing consultancy firm Dunnhumby engaged with this initiative on the strict premise that only businesses who met specific pre-agreed criteria were eligible for access. This criteria limited access to SMEs which employed no more than 250 employees and had a turnover of less than £10m, in accordance with EU regulations. This was strictly monitored throughout the three-year period of the initiative, with annual reports on usage.

Because of the nature of the data and the level of access available for SMEs, it was important that awareness of the initiative was spread across the whole region of Northern Ireland. This was achieved through the delivery of bi-monthly workshops in a specific food area at various Northern Ireland locations (hotels, local pubs and annual grower meetings), promoted by one of the co-author's and DARD representatives, with SMEs targeted using 
the DARD mailing list for each sector. DARD representatives provided guidance on firms that would be most likely to engage with communication. Using the direct access provided via the Government department, owner-managers of all SME agri-food and agri-drink firms were invited to a general workshop relevant to their sector (e.g. fresh vegetables, lamb, beef, eggs, bakery and prepacked meats) where they were introduced to Dunnhumby data, the background to the Government project, the role of the Dunnhumby data and what they could do.

Once awareness was achieved through the SME attendance at the workshops and promotion of the Dunnhumby data, the challenge was to ensure that the data were presented in a format that would be relevant, understandable and actionable. To meet this challenge, the data ere extracted from the Dunnhumby database, filtered and analysed by the facilitator (one of the co-authors) prior to the delivery of the workshops. This delivery took the format of a PowerPoint presentation, with the key information provided in a simplified graph, list or chart format. The list below gives an overview of key questions used in participant workshops:

Q1. "What is the value of my category year on year?"

Q2. "Who are the main competitors in this category?"

Q3. "What is the best performing product in this category?"

Q4. "What customers are buying my product (similar product)?"

Q5. "What else do customers purchase alongside my product (similar product)? "(Basket analysis).

Q6. "Where is the best performing region (area) for my product (similar product)?"

The awareness and understanding at the first workshop acted as a catalyst for SMEs requesting further information that was directly relevant to their specific product or product area. Based on the introductory workshop, a follow up one-to-one delivery of bespoke filtered data was offered to SMEs at a place and time of their choosing. The facilitator would travel to the business premises and deliver further information on a PowerPoint report, with each report point being explained fully by the facilitator and with free flow discussions. This required two-way communication between the owner-manager(s) and the facilitator and allowed them to drill down to potential and relevant questions by the owner-manager(s). These queries would address the key questions (as per Table I) but have a more specific focus - for example, "How is my product (or a similar product) performing in this category?" or "What was the impact of the most recent promotion on customer loyalty?"

Over the three-year period of the project, 300-plus firms engaged with the data, with seven in-depth case studies selected for the purposes of this study (Table I). These businesses were selected on a predetermined criterion using replication logic that is premised on the view that the undertaking of multiple cases is analogous to the undertaking of multiple experiments. The criteria used included the businesses that had never been previously exposed to Dunnhumby data, that the businesses represented a range of sub-sectors within the agri-food market, market channels and business lifecycles and that all

Table I Participating SME cases

SME

Case 1

Case 2

Case 3

Case 4

Case 5

Case 6

Case 7
Sector

Yoghurt

Soup

Health foods

Bakery

Mushroom

Tea

Ready meals
Business establishment

1988 
represented a premium niche market. This criterion, in conjunction with guidance from DARD representatives, as well as SME owner-managers' willingness to engage, provided a solid basis upon which seven case studies where selected. The application of replication logic to case selection is viewed as an essential part of multiple case analyses, enhancing confidence in emerging relationships and their validity. In this study, selecting SMEs from within the agri-food sector that exhibited a range of pre-determined characteristics allowed the researchers to examine the effect of a facilitated KM process applied to SMEs, derive a richer set of findings through the multiple case design and, more confidently, identify emerging relationships through within and between case analysis.

Case study research was chosen as the best methodology for this study, as it "tries to illuminate a decision or a set of decisions" (Yin, 1994, p. 12). Ultimately, the initiative provided SME owner-managers with the opportunity to engage with and use the Dunnhumby data as much as they wished, in return for insight into why the SME may or may not engage with the data, or how the SME did/did not utilise the data for business development over a period of time. The case study method adopted is shaped by the action research approach in which seven agri-food SME owner-managers were contacted by the facilitator at least once per month, with any other contact being initiated by the owner-managers. This action research approach allowed for "practical hands-on field research" (Crowther and Lancaster, 2009, p. 135) and "a planned intervention by a researcher" (Gill and Johnson, 1997, p. 59), with the ultimate goal of providing owner-managers with information and helping them to address some queries or challenges in the business.

The one year longitudinal study consisted of three main stages of research (Figure 1).

Stage 1 involved the carrying out of exploratory structured interviews attempting to ascertain how each agri-food case was performing marketing before exposure to the Dunnhumby data. The facilitator utilised a piloted schemata derived from the market orientation contract of Pelham and Wilson (1996) (see Appendix 1). This schemata was initially tested by three agri-food and drink experts. The results of the pilot were used in conjunction with an on-going review of extant literature, creating a pre-final questionnaire that was piloted at a sector workshop with agri-food SMEs. Stage 2 consisted of semi-structured interviews which were carried out on a six-month basis with SME owner-managers. These interviews took the form of an informal conversation which asked cases to discuss what was happening within the business at that time, how they were using the data (if at all) and whether they required any further follow-up reports. Interviews were carried out with one or both SME owner-managers and three types of communication

Figure 1 Longitudinal research study stages

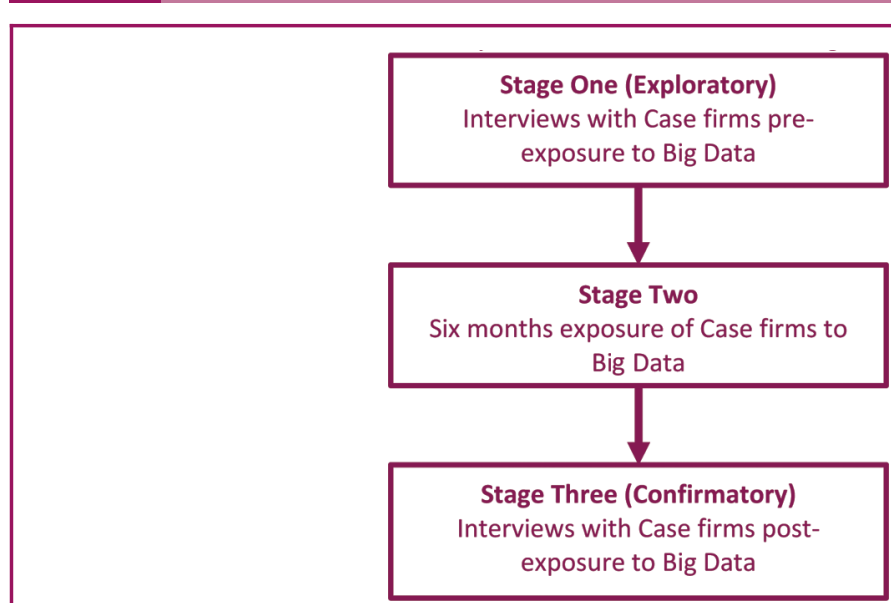

VOL. 21 NO. 12017 JOURNAL OF KNOWLEDGE MANAGEMENT | PAGE 163 
channels - telephone, personal meetings and email communication - and were maximised to observe and record the discussions with SMEs. Stage 3 included a confirmatory interview with cases attempting to ascertain how SMEs perform marketing post-exposure, using the standard schemata from Stage 1. In total, 24 formal interviews were carried out in conjunction with 18 informal meetings, 29 informal telephone conversations and 1 email communication (see Appendix 2 for summary of contact). All interviews were transcribed verbatim, and all email communications collected were used to support and verify the activities of the firms as discussed as per interview. This study adopted a template analysis as a means of categorising themes revealed through the complexity of mass volumes of qualitative data. The flexibility of the template analysis approach allowed for categories to be predetermined but also subsequently added to or amended as the data were collected (King, 2004).

\section{Findings}

The findings are discussed under eight themes. All eight stem directly from the structured and semi-structured interviews, with six linking directly to the reviewed literature and two presenting as emergent themes. The themes that were evident within the reviewed literature have been characterised under the headings "resources, "competitiveness", "power differentials", "networks", "knowledge" and "value". The two emergent themes have been characterised under the headings "risk management" and "family business". An overview of the findings is available in Table II (below).

\section{Resources}

The resources available to cases limited and/or stretched their capacity to develop as a business with C4P1 stating that "Cost is a huge barrier. There is no money". However there was evidence of investment in two of the cases, but this was typically in the growth of their business production efficiency and capacity. Despite the desire by some firms to grow, the day-to-day activities of half of the cases were deemed reactive, as C4P2 sums up: "[We] have a lot less resources now as there are less people and we have been stretched and we haven't had the time to be analysing the market or spend time on analysing Dunnhumby, sharing information, talking or doing. Instead we have been reacting to the situation as opposed to building strategy". Overall, the ability to act upon Dunnhumby data fully is constrained because of size, as C1P1 suggests: "We can come up with all the lovely ideas in the world and it is hard you know to put a lot of that into action".

\section{Competitiveness}

Cases demonstrated varying levels of competitiveness, as reflected in the range of strategic classifications adopted by the cases (Table II). Only Case 1 adopted the role of a defender as they consciously decided that as a firm they will adopt a capped growth strategy. Meanwhile, Case 4's reactor outlook appears to have grown with the creation of the business and the culture it exists in, with the attitude that the case bakes and people buy, with no customer input required. Case 5 provides an example of an analyser who likes to maintain a stable business, cautious to change but willing to act fast when the decision is made. For example, as C5P1 states, "It is simply because we have filled the factory now and sales are really good". In contrast, a prime example of a prospector is Case 3 as characterised by C3P1's statement that "what really excites the big retailers is our ability to innovate".

\section{Power differentials}

The power differentials evident varied both internally and externally in all cases. Depending on their size, cases shared data internally across top management who were responsible for decision-making. However, this did not always take place in a formal setting; often, this 


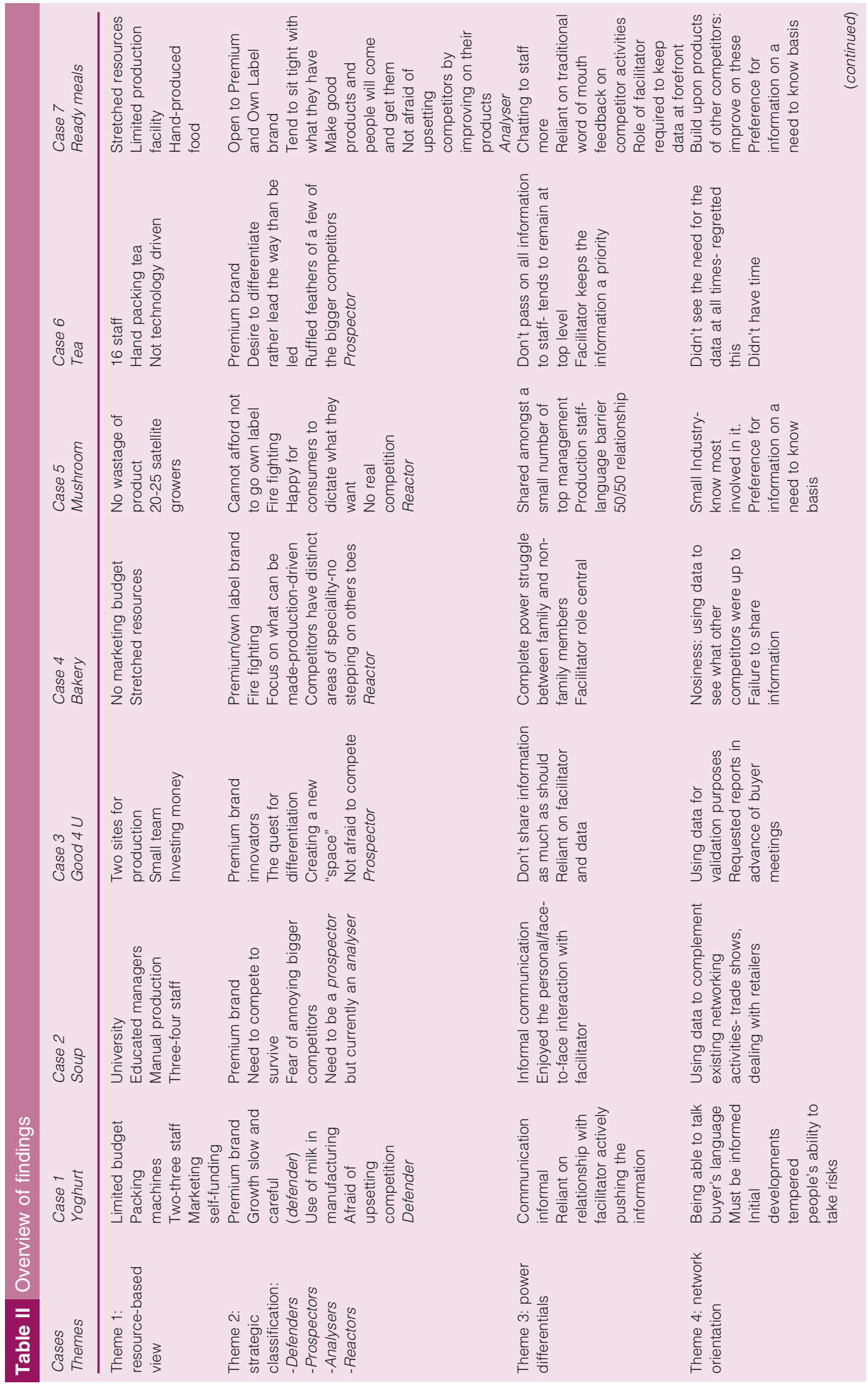




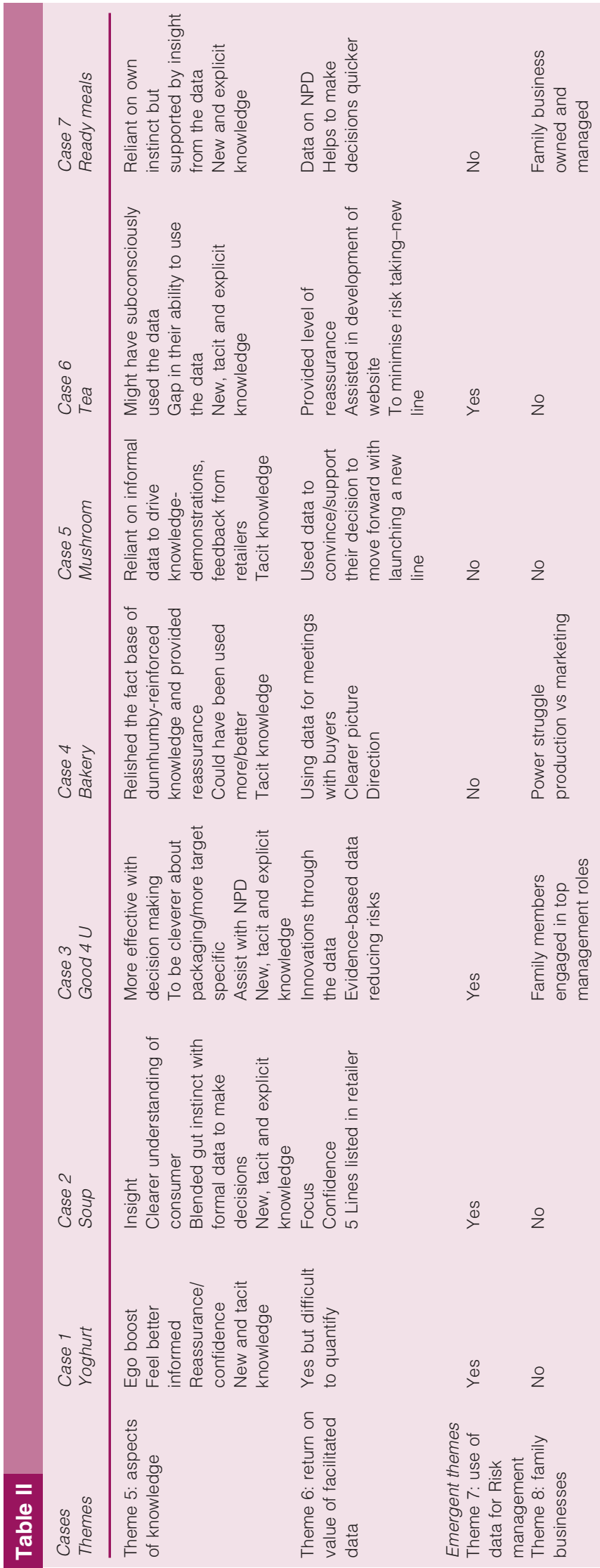


sharing of formalised data was undertaken in an informal manner or setting, such as during daily production activities. However Cases 2 and 3 actively tried to share data with all staff. According to C3P1, "It is so much better for everyone to understand who is actually buying our products and they [employees] are quite interested [...] ". The only exception to the sharing of information at any level was demonstrated in Case 4. This case experienced major power differentials internally amongst staff members comprising non-family and family members. Externally, cases often used the Dunnhumby data to facilitate meetings with buyers or to hold conversations or the attention of buyers for longer. C3P1 utilised the data to talk to buyers, stating that, "We would have put it [Dunnhumby data] into a format that they understood because we know that the buyers want us to know everything about their consumer".

Other perceived barriers due to power differentials existed between the SMEs and their major customers (retail buyers). It became apparent that prior to the exposure to data, SMEs were at the grace of their major client. However, with the exposure of data and the increased knowledge of the SME owner-manager on their product's market and confidence in their product's competitiveness, the SMEs presented a stronger partnership to the client.

Six out of seven cases welcomed the face-to-face interaction with the Dunnhumby data facilitator throughout the delivery of the project, with C2P2 suggesting that "It was good as we were able to go through it [the Dunnhumby report] and then ask you [facilitator] to clarify something". Having a facilitator present kept data relevant, making businesses more active in their use of the data. This was highlighted by C1P1, who stated that, "It was absolutely useful to have someone actively pushing us and you know pushing the information towards us", otherwise C1P1 perceived that this facilitation of data would have been "another thing that would have slipped further down the list of non- essential happenings". However, a major concern was the lack of "right people" that would be able to make sense of the data if the facilitator was not present, with C3P1 highlighting, "This is only as good as the people that is delivering this $[\ldots]$ ".

\section{Network orientation}

The behaviour of cases engaging with the facilitator and the Dunnhumby data varied in relation to the network theme, with three cases actively participating in the exchange of information and knowledge to advance their understanding of their end consumer, the market and their products over the full period of the project. These cases $(\mathrm{C} 1, \mathrm{C} 2$ and C3) utilised the information not only to support their current activities but often also to just keep abreast of any change. According to C1P1, when dealing with suppliers, it is important to be informed: "But you do find that you have to be able to quote things like, looking at the Dunnhumby stuff, and to show that you are serious about supporting them (retailer)". Cases that were more passive tended to welcome the data on a one-way and need-to-know basis when driven by a meeting with a retailer/buyer or category window review. However, there were a number of cases who believed they could have been more participative (C4, C5, C6 and C7) in this project and did show some regret on reflection. C6P1 conceded that "I think it was because we didn't see a need for it immediately there and I don't know if that is just me being arrogant or something like that [...] you know all this priceless information that we had whatever! It was not like that. I think we just missed an opportunity really". Case 7 demonstrated a cautious/safe orientation, with a short term focus as summed up by C7P2's attitude that only when there was "no growth or it [sales] is quiet", that the business will then be quick to act to opportunities (Clegg, 1989).

\section{Aspects of knowledge}

The creation of new, tacit and explicit knowledge is evident across various cases. It is clear that in five out of seven case studies, new knowledge was created. This new 
knowledge was centred on new understandings about their consumer. Case 1 stated that they mistakenly thought they knew who their consumer was, but now as a result of the data, they feel better informed. The information shared with Case 1 highlighted a slightly older consumer purchasing their products. As a result of this insight, C1P1 has encouraged all taste testing facilitators to focus on a slightly mature audience as opposed to young professionals. Tacit knowledge creation was evident in six out of seven cases, with the data serving as an ego boost, providing confidence and reinforcing gut instinct. C1P1 stated that the "It [Dunnhumby data] just gives you a confidence to know that you know you were doing something right at that stage". Explicit knowledge creation was evident in four out of seven cases; C2P2 suggested the need for a solid base of information: "I like to have the hard facts to base whatever I am saying on. At the end of the day you can talk more passionately about your products and more confidently about your product and where the opportunities are when you know you have something solid to base it on". Ultimately, the value of the data was excellently captured by C1P2: "we are learning about our business as well. But I don't think we are entirely there and that is why we need this information. Knowledge is power". C1P2 also stated that, "The more knowledge we could get about what is going on the better. Otherwise it is a stab in the dark".

\section{Return on value of facilitated data}

The difficulty in assessing the value of the facilitated project is in quantifying "value" derived from the use of the Dunnhumby data. Cases found it difficult to directly relate the data to their overall firm success. However, one case rephrases the question "Think where you would have been if you hadn't had done it" (C1P1). This owner-manager suggested "it is all a part of the big picture and it has proved to become an important and valuable part of the picture". There is no question that value has been created in some form, if not several forms (Normann, 2001). Cases C2, C3 and C6 could clearly illustrate the value of the data, with C2 successfully launching five lines of their soup into a major retailer and C3 developing a new seed product (a small 20G sachet of healthy seeds). Only one case acknowledged no direct financial value in return from the data, but C4P1 still highlighted that: "Dunnhumby definitely could become more useful as strategy becomes more market oriented". However value is not always measured in financial figures but realised through the "use" to the business, as highlighted by C5P2: "Now we did use part of it [Dunnhumby data] to help us, I suppose to convince us to move a step forward [...]". This idea of confidence and support was also reiterated by C7P2: "It just supports it and I suppose it gives you a bit more confidence going out into the market place with a product". It is evident that "datification" did take place through this research (Lycett, 2013). Five out of seven cases developed the ability to separate information and context, whilst in the cases of buyers meetings, there was clear evidence of liquification with the repackaging of information. However, it tended to be only those cases with a proactive/analyser orientation that demonstrated density, with the careful combination of their existent resources with the information.

\section{Risk management}

Two new themes emerged from the findings, the first being "risk management". It became apparent in several of the cases that owner-managers increased their ability to manage risk through the use and application of the Dunnhumby data. For example, C3P1 states: "Any market information that you get that is evidence based reduces the risk [. . . And that's where Dunnhumby comes in. So it does give you in-depth knowledge of your category, and your product that you would not have access to". One example of risk management was in Case 6; C6P1 decided against launching a white tea with fruit based on the results extracted from the Dunnhumby data. As C6P1 states, "we didn't go ahead with it (white and fruit tea) [ . . . Because it was a real poor seller within the data [Dunnhumby] that we got. 
Table III Enablers and barriers to SME engagement

SME

Engagement/Factors

Tangible asset

constraints

Fundamental

strategic orientation

Internal and external

network practices

Perceived and real power differentials

Knowledge

preferences and use
Enablers to SME engagement

Assets and finance to grow the business

Businesses with a prospector or analyser orientation

Horizontal engagement internally

One-to-one engagement leading to discursive reasoning externally Partnership with major clients

Explicit over tacit
Barriers to SME engagement

Limited assets and finance to grow the business Businesses with a defender or reactor orientation Top-down engagement internally Limited network engagement Passive to major clients

Tacit over explicit

I suppose it is the first time that we have ever sat down and researched is it worth it? Because in the past we have just gone 'we will try it, we will see [. . .]"

\section{Family businesses}

The second new theme was that of "family business", with three out of the seven participating cases being family businesses. The role/orientation of family members dictating direction of the firm played a significant role in the uptake of the project and the success of data being used, as evidenced by C4P2: "It comes about that the owner and his family are from the production end of things which is what you usually find in a lot of manufacturing companies, sales come after". The role of the family can restrict information sharing within the business to family members only. For example in Case 5, C5P2 suggests:

It would have been just a top level. You have to understand that a lot of our employees are working in the production area. We have the language barrier which is number one, and because we are such a small organisation, to take time out to start explaining to them, it just doesn't happen for us.

\section{Discussion}

The study examined a facilitated KM process incorporating filtered big data and its impact on small business competitiveness within an agri-food supply chain through two emergent research questions: $R Q 1$ and $R Q 2$ :

$R Q 1$. What are the barriers to and enablers of SME engagement with big data and how might these be overcome and/or aided through engagement with a facilitated big data process?

$R Q 2$. Does engagement with big data made available through a facilitated $\mathrm{KM}$ process affect SME understanding of big data, SME market knowledge, and SME competiveness?

\section{Enablers of and barriers to small- and medium-sized enterprise engagement}

It is evident in the literature that "today's data tsunami means that firms potentially have a huge and diverse amount of (big) data and analytical insights at their fingertips. All this data and information can help them avoid mistakes, make better decisions and become more efficient, profitable and competitive" (Vriens, 2013, p. 32). However, the ability of SMEs to engage with big data can evidently be enabled or limited by a myriad of factors that can manifest, including tangible asset constraints, fundamental strategic orientation, internal and external network practices, perceived and real power differentials and knowledge preferences and use (Table III). 
Tangible assets can include factors such as land and equipment, industry training and efficient organisational processes (McDowell et al., 2015). As evident in Table III, all case study firms were faced with resource constraints that limited or stretched their capacity to develop as a business. Based on this understanding, the facilitated process provided all cases with free and readily available filtered data whenever they desired. This removed some of the main unique resource requirements of big data (Erevelles et al., 2015). The main enabler of this process was the one-to-one engagement between the SME owner-manager and the facilitator of the data. Despite the readily available access to data and the desire of some cases to grow, some businesses could not see past the day-to-day activities of the business. In most instances, these cases were reacting or fire-fighting as opposed to being as proactive as they desired (Wincent, 2005). Even with access to filtered data, some cases did report that time, personnel, daily business pressures and finance impacted on their ability to fully utilise the filtered data provided. The cases, although enthused and excited about the data, recognised that they were somewhat limited as to how they could advance ideas generated from the free access to the data.

Case study firms also exhibited a range of behaviours and characteristics indicative of defenders, reactors, analysers and prospectors (Miles and Snow, 1978; Kabanoff and Brown, 2008) that seemingly influenced their engagement with and use of the facilitated big data that was made available to them. The defender case was one who adopted a slow growth policy, had decided that the firm would not grow beyond their own milk source and was afraid of upsetting competitors. This was a prime example of an in-built gut instinct and long-held belief that had become instilled in the business despite the great potential of the business to grow. This gut instinct and "safe" culture was also exhibited by the identified reactor case. These firms possibly failed to see the perceived value of the big data analytics exercise as much as the analysers and prospectors. The analyser case, however, despite being cautious to change, was still able to move fast when it did decide to act upon the information derived from the facilitated data, creating a new product. The prospector case thrived on new opportunities and was capable and willing to see an opportunity dissecting the data and using the outcome to support a business decision.

In network practices, the power differentials varied both internally and externally from case to case. It was evident that typically, the owner-manager who engaged with the data was central to all activity associated with the use of the data. This would support existing literature by Durst and Edvardsson (2012), who suggest that the central figure of control is the owner-manager. They are responsible for the management of knowledge identification, dissemination and application in the use of the filtered data. It was also the owner-manager's choice with whom to share the filtered data. Internally, cases, depending on their size, shared data across top management who were responsible for decision-making. In the small-sized case, firm's information appeared to be shared more openly and informally, whereas in the larger firms, the culture tended to restrict data sharing and if so, sharing was carried out at formal meetings or delivered to employees in production in one communication to all. However, three out of the seven cases actively tried to share data with all staff, acknowledging the important role of the employee in the decision-making process (Clegg, 1989). In the majority of cases, owner-managers relied largely on their own tacit knowledge, using the new filtered data knowledge for back-up, reinforcing the view that big data and human insight can co-exist (Donnelly et al., 2015).

However, when data were shared externally between cases and potential buyers/retailers or within their wider network, the information derived from the filtered data was given more prominence. The filtered data were used to facilitate meetings with buyers or to hold conversations or the attention of buyers for longer. Cases realised that the fact-based data and decisions demonstrated more credible and explicit understanding, allowing the SME to fully engage with the buyer/retailer as if they were a large business (McAfee and Brynjolfsson, 2012). It is apparent therefore that SMEs can utilise data in a professional 
manner for better prediction of individual action or choice surrounding their product offering(s) (Zhao et al., 2015). This is mutually beneficial for both the buyer and supplier and strengthens their relationship (Polychronakis et al., 2007).

The strength of word of mouth regarding the filtered data project was also evident through exchanges between cases and other businesses in their network. As a result of this, other small businesses were approaching the facilitator to discuss how they could participate in the project. The normal belief is that all SMEs struggle to engage with the government agencies that provide a support network (Fee et al., 2002), whereas this exchange of experience between SME networks demonstrated the perceived value and support of the project by the majority of the cases.

The passive or engaged nature of the SME case and the facilitator of the filtered data did emerge as an enabler or barrier to SME engagement with the facilitated data process. The majority of cases welcomed the face-to-face interaction with the data facilitator throughout the delivery of the project, with the exception of one case, suggesting that email or telephone was sufficient for communication of data. It was clear that the SME owner-managers welcomed the support from a like-minded person who was skilled in the facilitation of data to SMEs (Nolan, 2005, p. 12). In fact, this relationship over the longitudinal period was deemed critical to the motivation, proactivity and success of the SMEs using the data. Because of the restricted resource base of the SMEs, the facilitator was treated like one of the case's employees or a trusted advisor. This highlighted in some cases the over-reliance of the SME owner-managers on the facilitator to make sense of the data on their behalf, which in turn naturally impacted on the owner-manager's information management capability (Wamba et al., 2015).

\section{Small- and medium-sized enterprise understanding of big data, small- and medium-sized enterprise market knowledge and small- and medium-sized enterprise competitiveness}

The facilitated data process utilised in this study acknowledged the lack of SME financial strength to invest in "big data" (Wee and Chua, 2013) and in doing so provided SMEs with a unique situation in which data were free to access. There is limited research (if any) on what ways SMEs utilise data extracted from a big data set to demystify big data, create knowledge and improve competitiveness. Based on the research findings, SME utilisation varied based on their network orientation, their use of knowledge and their desired return on value from the data.

The role of the cases' engagement with the facilitator and the filtered data varied, with three case firms actively participating in the exchange of information and knowledge to advance their understanding of their consumer, the market and their products over the full term of the project. In doing so, they were able to "demystify data" for the first time using credible insight. These cases utilised the information not only to support their current activities but also often to just keep abreast of any change. However, passive cases tended to welcome the data on a one-way basis requesting data largely on a need-to-know basis driven by a meeting with a retailer/buyer or category window review (Nolan, 2005). Interestingly, there were cases which post-process believed they could have been more participative in this project and did show some regret on this matter once the project was finished. There was also a level of naivety in relation to the benefit of the data for some of the cases which believed that they only required the data when there was no growth in their business (Clegg, 1989).

The creation of new, tacit and explicit knowledge is evident across various cases. New knowledge was created in five out of seven case studies. This new knowledge was centred on a new understanding about their consumer. For many cases, this was the first real insight into who their consumer currently is. Until this point, SME owner-managers had relied largely on gut instinct (Coviello et al., 2000, p. 526). In almost all but one case, tacit knowledge creation was evident with the data serving as an ego boost, providing confidence, assurance and reinforcing gut instinct. This serves to illustrate the importance 
of human vision and insight in conjunction with evidence-based data (McAfee and Brynjolfsson, 2012; Donnelly et al., 2015). Explicit knowledge creation was evident in four out of seven cases, as cases realised the need and importance for a solid base of information to assist in new product development and ultimately decision-making.

The awareness of the need for knowledge and the power of knowledge are highlighted in this research. The thirst for solid facts, reliable and credible figures is evident, reducing cases' need to take a "stab in the dark" (C1P2). The filtered data have helped guide the cases to secure listings and to build a stronger relationship with buyers/retailers. This is even more critical considering the hyper competitive nature of the agri-food industry (Erevelles et al., 2008).

The overall ability of SME owner-managers to improve competitiveness of their business through the utilisation of the filtered data varied. The quantifying of "competitiveness" and "value" based on the use of the filtered data is difficult in this study, as the nature of the data is long term and therefore challenging to directly relate to overall firm success. Gorgievski et al. (2011) acknowledged the need for a better understanding of the subjective success criteria of small business owners, not just the financial success. Cases were very assured in what they perceived as the success of the use of the data. In the majority of cases, SME owner-managers believed that the data did contribute to the firm's overall competitiveness on two main levels, that is, both personally and financially. Personally, SME owner-managers felt that they were more informed and confident decision makers, creating a new culture within their organisation for sharing of information (Clegg, 1989), as well as instilling a balance of human instinct being accompanied by fact-based data (Donnelly et al., 2015). In addition, they felt supported by the data and the infrastructure of the project to progress and to be able to make sense of and to relate the data to other people both inside and outside of the business. Financially, three cases can clearly illustrate the value of the data to their overall competitiveness, with some cases successfully launching new lines into major retailers, developing new product offerings and innovating within their existing operations. The only case which did not exhibit any level of competitiveness as a result of the filtered data blamed their firm's internal restrictive culture for failure to utilise and to share the data amongst employees.

Overall, based on this research, there is evidence to support Wamba et al.'s (2015) belief that there is an element of uncertainty by adopters of "big data" in understanding what it actually is and how to capture value from it. Despite the facilitated nature of this knowledge process, barriers do exist, which restricted the ability of the SME cases to successfully understand, apply and reap rewards from this data. These barriers typically included resource issues such as lack of finance and personnel, but not all barriers are tangible. In some cases, owner-managers have chosen not to "advance" out of fear of overgrowing or risk (Stenholm, 2011) and/or even upsetting competitors. However, those cases which engaged successfully with the facilitated data process did demonstrate sense making, new knowledge and increased competitiveness. Ultimately, it is crucial that big knowledge is packaged in the right way for small businesses, and that small businesses are in the "right" mind-set and growth stage to openly engage and utilise the opportunities which can be derived from facilitated data. In reality, SMEs do need big data too (Donnelly and Simmons, 2013), as big data not only can provide opportunities for developments but also can reduce risks by facilitating informed decision-making. Risk management is crucial for SMEs, as a major risk can ultimately destroy a business. SME owner-managers can successfully engage with and utilise big data just as larger business do but ultimately cannot act on the data to the extent of larger businesses because of the SME's inherent resource limitations.

\section{Implications for policy and practice}

There is evidence from this research that not all SMEs want to grow (Orser et al., 2000) and they do not demonstrate the innovative behaviour to grow (Stenholm, 2011). In this 
research, the cases which demonstrated analyser or prospector behaviour (Miles and Snow, 1978; Kabanoff and Brown, 2008) were best placed to engage with the facilitated data project because of their more innovative and/or aggressive behaviour (Miles and Snow, 1978). Ideally, these are the firms which should be selected to engage in future projects.

It is clear that realistic expectations must be discussed between the facilitating programme and the engaged SME. Ultimately, the inherent resources of the SME restrict the actions that SMEs can undertake when they attempt to demystify the data and create knowledge to improve competitiveness. However, it does not inhibit their capability to act on this data at a later stage when resources are more readily available. Funding provided by Government is critical and welcomed, but this is not the only evident challenge. Ultimately SMEs are not big businesses (Welsh and White, 1981), and so their resource limitations can restrain the full and or desired roll out of their understanding. This is understandably frustrating for owner-managers in possession of such rich insight, but evidence from this research suggests that small businesses need big data to build a competitive business.

As highlighted earlier, it was clear that the SME owner-managers welcomed the support from a like-minded person who was skilled in the facilitation of data to SMEs (Nolan, 2005, p. 12). However, this all-encompassing role held by the facilitator was not without its concerns and challenges. These included an over-reliance by cases on the facilitator and/or the inability of the facilitator to work with all cases in the wider project (outside of the seven case studies) at the same rate/consistency because of time constraints. It would be beneficial for future studies if more training was provided to more case firm employees so that sharing and understanding was not held by the facilitator and owner-manager alone and that the skill set required to read, understand, analyse and apply the data was shared more broadly and supported by continued training. This could also be important for government support bodies or executives who could be trained to support the dissemination of data of this type or other business intelligence. In short, the danger is that an over-reliance on one facilitator is not conducive to the long-term rollout of a data facilitation project.

\section{Implications for future research}

Theoretically, this research serves to reinforce the important research link between aspects of knowledge and competitiveness in SMEs. The tacit versus explicit knowledge preferences in the SME's orientation was displayed but in a complimentary nature (Donnelly et al., 2015), as SMEs used the explicit knowledge derived from the data to support their existing tacit knowledge and gut instinct behaviour. The research also extends upon the Kabanoff and Brown's (2008) study of knowledge structures used by top management teams within a large firm environment, and advances evidence that defenders and reactors typically do place less value on big data and analytics exercises, whereas prospectors and analysers see an opportunity to discern information that would support discursive reasoning. The individual differences between case firm owner/managers can impact the uptake and use of real data on their decision-making. Potentially, future studies could consider theories from behavioural science to help explain this phenomenon and perhaps provide some guidance to Government and facilitators of the data to managing it.

SMEs also demonstrated in this study their reluctance to engage with an initiative designed for their benefit and appear to have done so not only because of a lack of technical expertise but also because of their preference for information and knowledge on a "need-to-know", "how to" and "who with" basis (Nolan, 2005). Therefore future studies could revisit these case firms a number of years after completion of the study to gauge their own reflection on the use of the data at the timeframe. Also, future studies could include a 
wider range of big data sets such as Mintel, TNS and Data Monitor to test exposure and use on a larger scale.

\section{Limitations of this study}

The main limitation of this research is the use of only one form of big data; by using Dunnhumby data, this study captured the impact of only one form of big data consumer analytics. However, this is a significant data set for SME agri-food businesses. The study demonstrates the potential of big data to SMEs' daily activities and developments while explicitly identifying that to realise this potential, the data need to be filtered and presented as market-relevant information in a manner that engages SMEs, recognises relationship dynamics and supports learning through feedback and two-way dialogue. This is the first study that empirically analyses the potential of filtered big data and SME competitiveness with potential for a wider scope for future research across multiple regions of the UK with the same Dunnhumby data set.

\section{Conclusion}

This research supports and builds upon Massaro et al.'s (2016) research on KM within SMEs and furthering Durst and Edvardsson (2012) call for further research into SMEs and $\mathrm{KM}$. The research outcomes also reinforce that knowledge can be a strategic asset using RBT and demonstrates that explicit knowledge coupled with the right strategic orientation can underpin SME competitiveness.

The research specifically demonstrated that SME access to and understanding of big data and big data consumer analytics, in particular, is confounded by firm-specific resource constraints, SME's strategic orientation, traditional patterns of information access and use and power differentials. SME resource constraints in particular have been widely discussed in the literature, and therefore, this study reinforces a widely reported barrier. Likewise, a preference for tacit over explicit knowledge within the SME community has been well documented.

However, power differentials within value networks that distort communication and understanding between SMEs and large, data rich, downstream wholesalers and retailers has not previously been recognised as an immediate barrier to big data use by SMEs. Likewise, the strategic orientation of SMEs, which in this study was assessed using the Miles and Snow typology of prospectors, analysers, reactors and defenders has not previously been identified as a barrier in this context. It is notable that this is the first study to identify that the strategic orientation of an SME's direct impacts upon their proactive engagement with the explicit knowledge that can be derived from a facilitated $\mathrm{KM}$ programme and in particular one linked to big data consumer analytics.

Our research also challenges the beliefs of Ghobadian and Gallear (1996) that within SMEs, tacit knowledge wins over that of explicit knowledge. In fact, our research demonstrates the use of explicit knowledge in decision-making, as well as case examples of explicit and tacit knowledge being used to support a decision. Despite the positive nature of this research, there still remains an element of uncertainty as to how all types of firms (as well as SMEs) can capture "value" from data (Wamba et al., 2015).

To conclude, this research highlights the need for small businesses to have access to big data to strengthen their knowledge and their management of data in what has become a very competitive global market place. Specifically, it has also demonstrated the role played by SME strategic orientation and knowledge preferences and the potential of facilitated KM programme to overcome SME-based limitations and the impact of power differentials that distort communication in large and complex value chains.

PAGE 174 | JOURNAL OF KNOWLEDGE MANAGEMENT | VOL. 21 NO. 12017 


\section{Notes}

1. Dunnhumby is the organisation responsible for the management and processing of the Tesco Club Card data.

2. The Dunnhumby project is a three-year facilitation of high-level market intelligence data deriving from the Tesco Clubcard data, which are delivered to all SME agri-food firms across Northern Ireland.

\section{References}

AFSB (2013), "Going for growth: a strategic action plan in support of the Northern Ireland Agri-Food Industry", available at: www.agrifoodstrategyboard.org.uk/uploads/Going\%20for\%20Growth\% 20-\%20Web\%20Version.PDF (accessed 21 July 2016).

Angiuli, O., Blitzstein, J. and Waldo, J. (2015), "How to identify your data", Communications of the ACM, Vol. 58 No. 12 , pp. 48-55.

Barney, J.B. (1991), "Firm resources and sustained competitive advantage", Journal of Management, Vol. 17 No. 1, pp. 99-120.

Blackburn, R., Hart, M. and Wainwright, T. (2013), "Small business performance: business, strategy and owner-manager characteristics", Journal of Small Business and Enterprise Development, Vol. 20 No. 1, pp. 8-27.

Clegg, S.R. (1989), Framework of Power, Sage, London.

Coviello, N.E., Brodie, R.J. and Munro, H.J. (2000), "An investigation of marketing practice by firm size", Journal of Business Venturing, Vol. 15 Nos 5/6, pp. 523-545.

Crowther, D. and Lancaster, G. (2009), Research Methods: A Concise Introduction to Research in Management and Business Consultancy, Second edn, Elsevier, London.

Davenport, T., De Long, D.W. and Beers, M.C. (1998), "Successful knowledge management projects", Sloan Management Review, Vol. 39 No. 2, pp. 43-57.

Donnelly, C. and Simmons, G. (2013), "Small businesses need big data, too", Harvard Business Review Blog, available at: https://hbr.org/2013/12/small-businesses-need-big-data-too/ (accessed 29 March 2016).

Donnelly, C., Simmons, G., Armstrong, G. and Fearne, A. (2015), "Digital loyalty card 'big data' and small business marketing: formal versus informal or complementary?", International Small Business Journal, Vol. 33 No. 4, pp. 422-442.

Dunn, E. (2006), It's Marketing Jim, But Not as We Know It, 1st ed., Dunnhumby, London.

Durst, S. and Edvardsson, I.R. (2012), "Knowledge management in SMEs: a literature review", Journal of Knowledge Management, Vol. 16 No. 6, pp. 879-903.

Erevelles, S., Fukawa, N. and Swayne, L. (2015), "Big data consumer analytics and the transformation of marketing", Journal of Business Research, Vol. 69 No. 2, pp. 897-904.

Erevelles, S., Stevenson, T.H., Srivinivasan, S. and Fukawa, N. (2008), "An analysis of B2B ingredient co-branding relationships", Industrial Marketing Management, Vol. 37, pp. 940-952.

Fee, R., Erridge, A. and Hennigan, S. (2002), "SMEs and government purchasing in Northern Ireland: problems and opportunities", European Business Review, Vol. 14 No. 5, pp. 326-334.

Fit For Market (2004), Food Strategy Group, DARD/DETI, Belfast.

Fletcher, L. and Polychronakis, Y.E. (2007), "Capturing knowledge management in the supply chain", European Mediterranean Journal of Business, Vol. 2 No. 2, pp. 191-202.

Ghobadian, A. and Gallear, D.N. (1996), "Total quality management in SMEs", Omega, Vol. 24 No. 1, pp. 83-106.

Gill, J. and Johnson, P. (1997), Research Methods for Managers, Second edn, Paul Chapman Publishing, London.

Gobble, M.M. (2013), "Big data: the next big thing in innovation", Research Technology Management, Vol. 56 No. 1, pp. 64-66. 
Gorgievski, M.J., Ascalon, M.E. and Stephan, U. (2011), "Small business owners' success criteria, a values approach to personal differences", Journal of Small Business Management, Vol. 49 No. 2, pp. 207-232.

Jennings, P. and Beaver, G. (1997), "The performance and competitive advantage of small firms: a management perspective", International Small Business Journal, Vol. 15 No. 2, pp. 63-75.

Kabanoff, B. and Brown, S. (2008), "Knowledge structures of prospectors, analysers, and defenders: content, structure, stability, and performance", Strategic Management Journal, Vol. 29 No. 2, pp. 149-171.

Kakabadse, N.K., Kouzmin, A. and Kakabadse, A. (2001), "From tacit knowledge to knowledge management: leveraging invisible assets, knowledge and process management", Journal of Knowledge Management, Vol. 8 No. 3, pp. 137-215.

Kelly, S. and Scott, D. (2012), "Relationship benefits: conceptualization and measurement in a business-to-business environment", International Small Business Journal, Vol. 30 No. 3, pp. 310-339.

King, N. (2004), "Using templates in the thematic analysis of text", in Cassell, C. and Symon, G. (Eds), Essential Guide to Qualitative Methods in Organisational Research, First edn, Sage Publications, London.

Liu, Y., He, J., Guo, M. and Yang, Q. (2014), "An overview of big data industry in China", China Communications, Vol. 11 No. 12, pp. 1-10.

Lycett, M. (2013), "Datafication': making sense of (big) data in a complex world", European Journal of Information Systems, Vol. 22 No. 4, pp. 381-386.

McAdam, R. and Reid, R. (2001), "SME and large organisation perceptions of knowledge management: comparisons and contrasts", Journal of Knowledge Management, Vol. 5 No. 3, pp. 231-241.

McAfee, A. (2013), "Big data's biggest challenge? Convincing people NOT to trust their judgement", Harvard Business Review Blog, available at: https://hbr.org/2013/12/big-datas-biggest-challengeconvincing-people-not-to-trust-their-judgment/ (accessed 19 March 2016).

McAfee, A. and Brynjolfsson, E. (2012), "The management revolution", Harvard Business Review, 1 October, pp. 61-69.

McDowell, W.C., Harris, M.L. and Gehoa, P.R. (2015), "Longevity in small business: the effect of maturity on strategic focus and business performance", Journal of Business Research, Vol. 69 No. 5 , pp. 1904-1908.

Manyika, J., Chui, M., Brown, B., Bughin, J., Dobbs, R., Roxburg, C. and Byers, A.H. (2011), Big Data: The next Frontier for Innovation, Competition and Productivity, McKinsey Global Institute, New York, NY.

Massaro, M., Handley, K., Bagnoli, C. and Dumay, J. (2016), "Knowledge management in small medium enterprises: a structured literature review", Journal of Knowledge Management, Vol. 20 No. 2, pp. 258-291.

Miles, R.E. and Snow, C.C. (1978), Organizational Strategy, Structure, and Process, McGraw-Hill, New York, NY.

Nolan, T. (2005), "Engaging with SMEs: power, politics and communication", International Journal of Sociology and Social Policy, Vol. 25 No. 8, pp. 1-17.

Normann, R. (2001), Reframing Business: When the Map Changes the Landscape, Sussex, John Wiley and Sons, Chichester.

Orser, B.J., Hogarth-Scott, S. and Riding, A.L. (2000), "Performance, firm size and problem solving", Journal of Small Business Management, Vol. 38 No. 4, pp. 42-58.

Pelham, A.M. and Wilson, D.T. (1996), "Longitudinal study of the impact of market structure, firm structure, strategy, and market orientation culture on dimensions of small-firm performance", Journal of the Academy of Marketing Science, Vol. 24 No. 1, pp. 27-43.

Perrey, J., Spillecke, D. and Umblijs, A. (2013), Smart Analytics: How Marketing Drives Short-Term and Long-Term Growth, McKinsey Q, New York, NY.

Polychronakis, Y.E. and Syntetos, A.A. (2007), "'Soft' supplier management related issues: an empirical investigation", International Journal of Production Economics, Vol. 106 No. 2, pp. 431-449. 
Ring, P. and Van de Ven, H. (1994), "Developmental processes of cooperative interorganizational relationships", The Academy of Management Review, Vol. 19 No. 1, pp. 90-118.

Stenholm, P. (2011), "Innovative behaviour as a moderator of growth intentions", Journal of Small Business Management, Vol. 49 No. 2, pp. 233-251.

Valkokari, K. and Helander, N. (2007), "Knowledge management in different types of strategic SME networks", Management Research News, Vol. 30 No. 8, pp. 597-608.

Vriens, M. (2013), "How integrated analytics tools help researchers make smarter, faster decisions", Marketing Research, Chicago, IL, pp. 32-38.

Wamba, S., Akter, S., Edwards, A., Chopin, G. and Gnanzou, D. (2015), "How 'big data' can make big impact: findings from a systematic review and a longitudinal case study", International Journal of Production Economics, Vol. 165 No. 1, pp. 234-246.

Wee, J. and Chua, A. (2013), "The peculiarities of knowledge management processes in SMEs: the case of Singapore", Journal of Knowledge Management, Vol. 17 No. 6, pp. 958-972.

Welsh, J.A. and White, J.F. (1981), "A small business is not a little big business", Harvard Business Review, Vol. 59 No. 4, pp. 18-32.

Wincent, J. (2005), "Does size matter? A study of firm behaviour and outcomes in strategic SME networks", Journal of Small Business and Enterprise Development, Vol. 12 No. 3, pp. 437-453.

Yin, R.K. (1994), Case Study Research: Design and Methods, Sage Publications, London.

Zhao, X., Yeung, K.H., Huang, Q. and Song, X. (2015), "Improving the predictability of business failure of supply chain finance clients by using external big dataset", Industrial Management \& Data Systems, Vol. 115 No. 9, pp. 1683-1703.

\section{Further reading}

European Commission (2015), "User guide to the SME definition, extract of Article 2 of the annex to Recommendation 2003/361/EC", available at: http://ec.europa.eu/growth/smes/business-friendlyenvironment/sme-definition/index_en.htm (accessed 29 March 2016).

\section{Corresponding author}

Christina O'Connor can be contacted at: christina.oconnor@nuim.ie 


\section{Appendix 1}

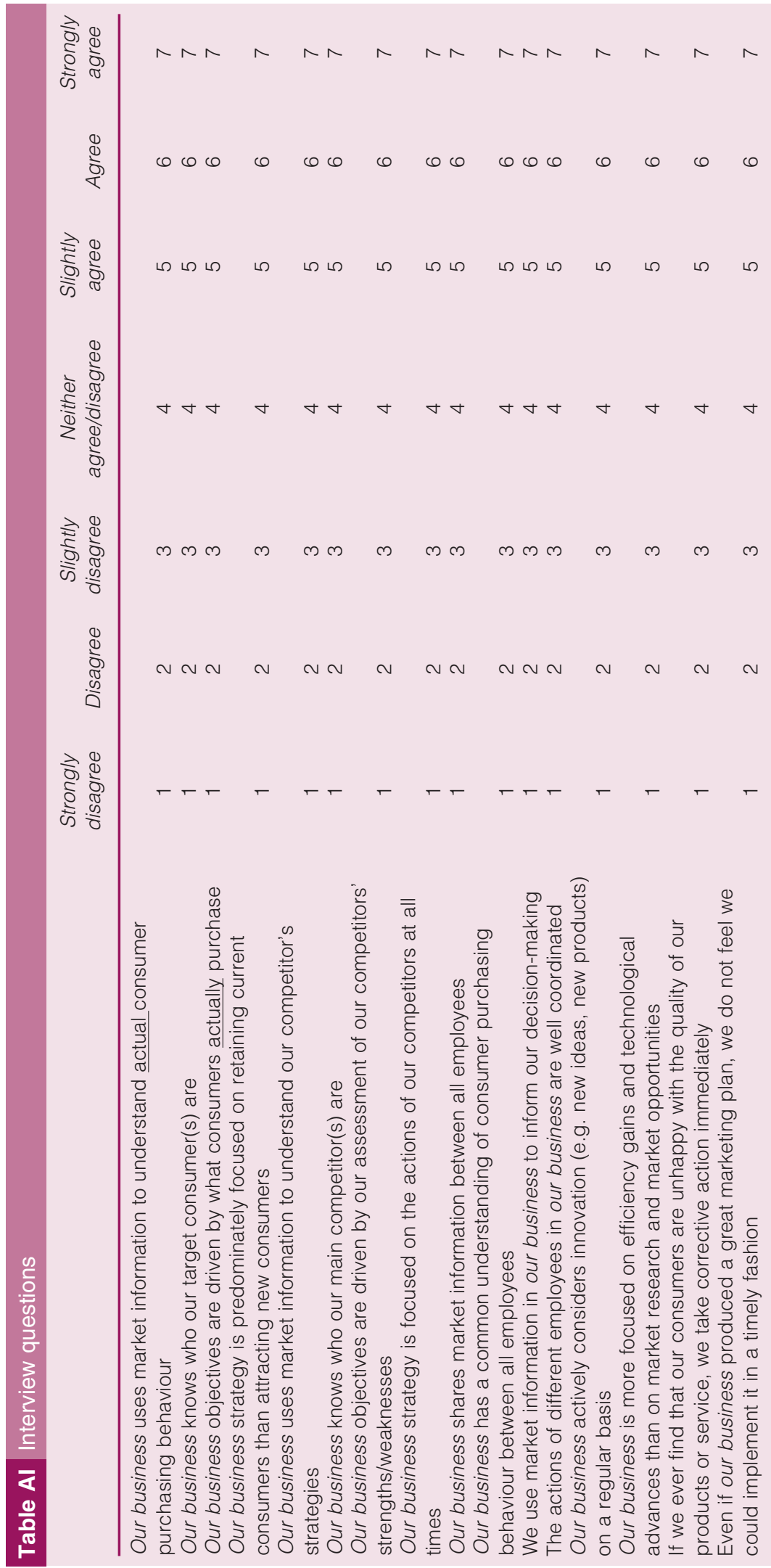




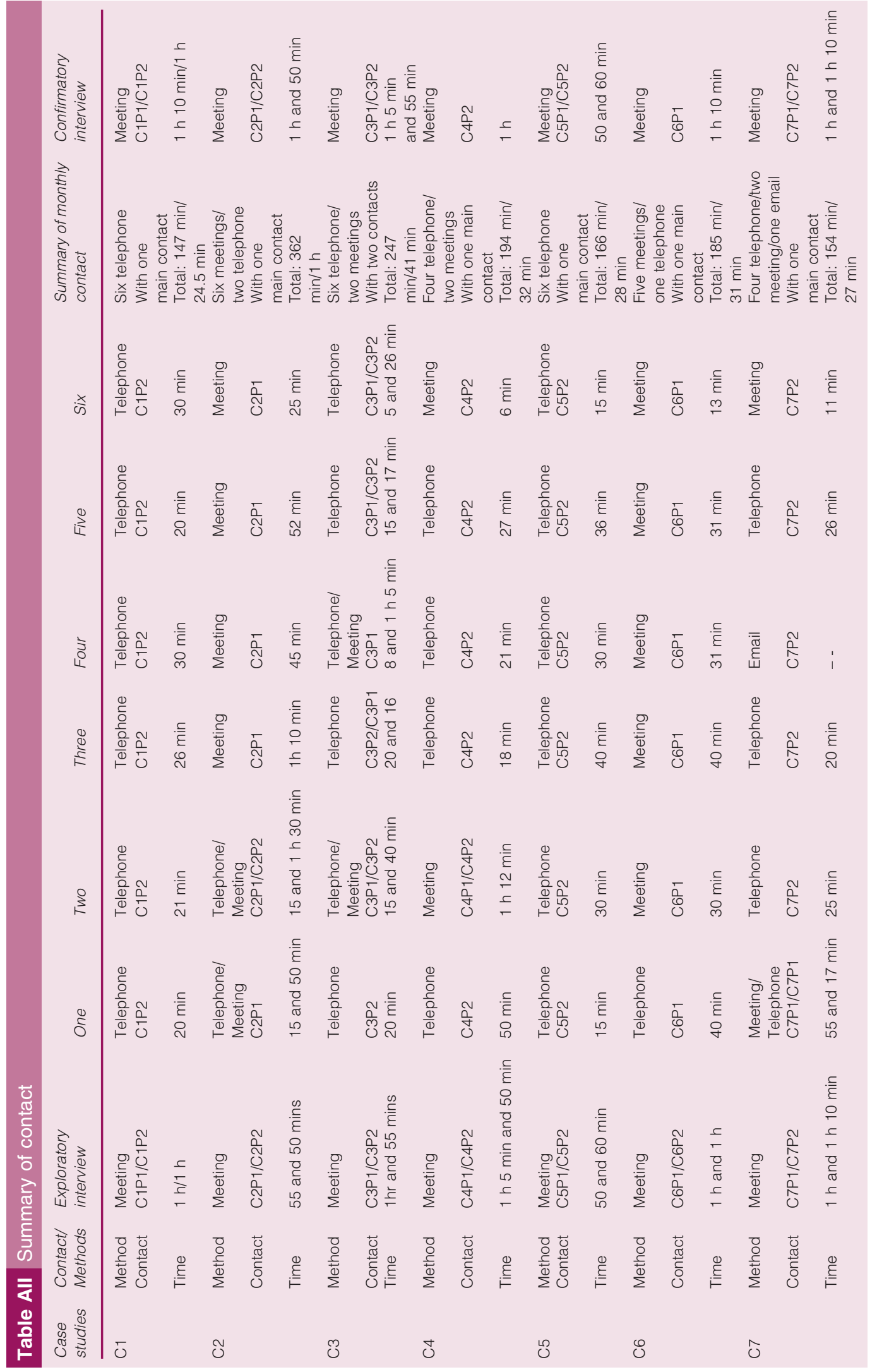

